\title{
Common fixed points of multivalued F-contractions on metric spaces with a directed graph
}

\author{
Mujahid Abbas ${ }^{1,2}$, Monther R. Alfuraidan ${ }^{3}$ and TAlat NaZir ${ }^{4,5}$
}

\section{ABSTRACT.}

In this paper, we establish the existence of common fixed points of multivalued $F$-contraction mappings on a metric space endowed with a graph. An example is presented to support the results proved herein. Our results unify, generalize and complement various known comparable results in the literature.

Acknowledgement. The authors thank editor and reviewers for their valuable suggestions that helped us to improve the final version of the paper. The second author is grateful to King Fahd University of Petroleum and Minerals for supporting this research.

\section{REFERENCES}

[1] Abbas, M., Ali, B. and Romaguera, S., Fixed and periodic points of generalized contractions in metric spaces, Fixed Point Theory Appl, 2013, 2013:243, 11 pp.

[2] Abbas, M., Ali, B. and Romaguera, S., Generalized contraction and invariant approximation results on nonconvex subsets of normed spaces, Abstr. Appl. Anal., 2014, Art. ID 391952, 5 pp.

[3] Abbas, M., Khamsi, M. A. and Khan, A. R., Common fixed point and invariant approximation in hyperbolic ordered metric spaces, Fixed Point Theory Appl., 2011, 2011:25, 14 pp.

[4] Abbas, M. and Nazir, T., Common fixed point of a power graphic contraction pair in partial metric spaces endowed with a graph, Fixed Point Theory Appl., 2013, 2013:20, 8 pp.

[5] Abbas, M., Nazir, T. and Radenović, S., Common fixed points of four maps in partially ordered metric spaces, Appl. Math. Lett., 24 (2011), 1520-1526

[6] Abbas, M., and Rhoades, B. E., Fixed point theorems for two new classes of multivalued mappings, Appl. Math. Lett., 22 (2009), 1364-1368

[7] Acar, O., Durmaz, G. and Minak, G., Generalized multivalued F-contractions on complete metric spaces, Bull. Iranian Math. Soc., 40 (2014), No. 6, 1469-1478

[8] Aleomraninejad, S. M. A., Rezapoura, Sh. and Shahzad, N., Some fixed point results on a metric space with a graph, Topology Appl., 159 (2012), 659-663

[9] Altun, I. and Simsek, H., Some fixed point theorems on ordered metric spaces and application, Fixed Point Theory Appl., 2010, Art. ID 621469, 17 pp.

[10] Beg, I. and Butt, A. R., Fixed point of set-valued graph contractive mappings, J. Inequal. Appl., 52 (2013), 7 pp.

[11] Berinde, V., Approximating fixed points of weak contractions using the Picard iteration, Nonlinear Anal. Forum, 9 (2004), No. 1, 43-53

[12] Berinde, V., Iterative Approximation of Fixed Points, Springer-Verlag, Berlin-Heidelberg, 2007

[13] Berinde, M. and Berinde, V., On a general class of multivalued weakly Picard mappings, J. Math. Anal. Appl., 326 (2007), 772-782

[14] Berinde, V., General constructive fixed point theorems for Ciric -type almost contractions in metric spaces, Carpathian J. Math., 24 (2008), No. 2, 10-19

[15] Bojor, F., On Jachymski's theorem, An. Univ. Craiova Ser. Mat. Inform., An. Univ. Craiova Ser. Mat. Inform., 40 (2013), No. 1, 23-28

[16] Bojor, F., Fixed point theorems for Reich type contractions on metric spaces with a graph, Nonlinear Anal., 75 (2012), 3895-3901

Received: 07.01.2015; In revised form: 12.03.2015; Accepted: 19.03.2015

2010 Mathematics Subject Classification. 47H10, 54H25, 54E50.

Key words and phrases. Common fixed point, multivalued mapping, directed graph, graphic.

Corresponding author: Mujahid Abbas; mujahid.abbas@up.ac.za 
[17] Chifu, C. I. and Petrusel, G. R., Generalized contractions in metric spaces endowed with a graph, Fixed Point Theory Appl., 2012, 2012:161, 9 pp.

[18] Gwozdz-Lukawska, G. and Jachymski, J., IFS on a metric space with a graph structure and extensions of the Kelisky-Rivlin theorem, J. Math. Anal. Appl., 356 (2009), 453-463

[19] Jachymski, J., The contraction principle for mappings on a metric space with a graph, Proc. Amer. Math. Soc., 136 (2008), 1359-1373

[20] Jachymski, J. and Jozwik, I., Nonlinear contractive conditions: a comparison and related problems, Banach Center Publ., 77 (2007), 123-146

[21] Kannan, R., Some results on fixed points, Bull. Calcutta. Math. Soc., 60 (1968), 71-76

[22] Latif, A. and Beg, I., Geometric fixed points for single and multivalued mappings, Demonstratio Math., 30 (1997), No. $4,791-800$

[23] Markin, J. T., Continuous dependence of fixed point sets, Proc. Amer. Math. Soc., 38 (1973), 545-547

[24] Minak, G., Helvasi, A. and Altun, I., Ciric type generalized F-contractions on complete metric spaces and fixed point results, Filomat 28 (2014), No. 6, 1143-1151

[25] Nieto, J. J. and Lopez, R. R., Contractive mapping theorems in partially ordered sets and applications to ordinary differential equations, Order 22 (2005), 223-239

[26] Nicolae, A., O'Regan, D. and Petrusel, A., Fixed point theorems for singlevalued and multivalued generalized contractions in metric spaces endowed with a graph, J. Georgian Math. Soc., 18 (2011), 307-327

[27] Ran, A. C. M. and Reurings, M. C. B., A fixed point theorem in partially ordered sets and some application to matrix equations, Proc. Amer. Math. Soc., 132 (2004), 1435-1443

[28] Rus, I. A., Petrusel, A., and Sintamarian, A., Data dependence of fixed point set of some multivalued weakly Picard operators, Nonlinear Anal., 52 (2003) 1944-1959

[29] Sgroi, M. and Vetro, C., Multi-valued F-Contractions and the Solution of certain functional and integral equations, Filomat, 27 (2013), No. 7, 1259-1268

[30] Wardowski, D., Fixed points of new type of contractive mappings in complete metric spaces, Fixed Point Theory Appl., 2012, 2012:94, 6 pp.

${ }^{1}$ Department of Mathematics and Applied Mathematics

UNIVERSITY PRETORIA

LYNNWOOD RoAD, PRETORIA 0002, SOUTH AFrica

${ }^{2}$ Department of Mathematics

KING ABDULAZIZ UNIVERSITY

P.O. BOX 80203, JEDDAH 21589, SAUdi ARABIA

E-mail address: mujahid.abbas@up.ac.za

3 Department of Mathematics \& Statistics

King Fahd University of Petroleum and Minerals

DHAHRAN 31261, SAUdi ARABIA

E-mail address: monther@kfupm.edu.sa

${ }^{4}$ Department of Mathematics

COMSATS INSTITUTE OF INFORMATION TECHNOLOGY

ABBOTTABAD 22060, PAKISTAN

${ }^{5}$ Division of Applied Mathematics, School of Education, Culture and Communication

Mlardalen University, 72123 VSters, SWEDEN

E-mail address: talateciit.net.pk 